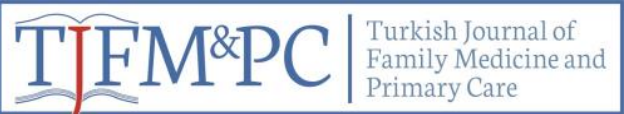

Review Article / Derleme

\title{
Global Tobacco Epidemic and Tobacco Control
}

\author{
Küresel Tütün Kullanımı Salgını ve Kontrolü
}

Toker Ergüder ${ }^{* 1}$

\begin{abstract}
The tobacco epidemic is one of the biggest public health threats the world has ever faced, killing more than 7 million people a year. While more than 6 million of those deaths results from direct tobacco use, around 890000 result from second-hand smoke in nonsmokers. Around $80 \%$ of the 1.1 billion smokers worldwide live in low- and middle-income countries. The WHO Framework Convention on Tobacco Control (WHO FCTC) entered into force in February 2005 and has today 181 parties covering more than $90 \%$ of the world's population. The WHO FCTC is a milestone in the promotion of public health and an evidence-based treaty that reaffirms the right of people to the highest standard of health, provides legal dimensions for international health cooperation and sets high standards for compliance. In 2008, WHO introduced a practical, cost-effective way to scale up implementation of the main demand reduction provisions of the WHO FCTC on the ground: MPOWER. Each MPOWER measure corresponds to at least 1 provision of the WHO Framework Convention on Tobacco Control. The 6 MPOWER measures include monitoring tobacco use and prevention policies, protecting people from tobacco use, offering help to quit tobacco use, warning about the dangers of tobacco, enforcing bans on tobacco advertising, promotion and sponsorship and raising taxes on tobacco. Only 1 in 3 countries, representing $39 \%$ of the world's population, monitors tobacco use by repeating nationally representative youth and adult surveys at least once every 5 years. National comprehensive cessation services with full or partial cost-coverage are available to assist tobacco users to quit in only 26 countries, representing $33 \%$ of the world's population. 78 countries, representing $47 \%$ of the world's population, meet the best practice for pictorial warnings. Around $44 \%$ of the world's population live in the 43 countries that have aired at least 1 strong antitobacco mass media campaign within the last 2 years. Only 37 countries, representing $15 \%$ of the world's population, have completely banned all forms of tobacco advertising, promotion and sponsorship. Only 32 countries, with $10 \%$ of the world's population, have introduced taxes on tobacco products so that more than $75 \%$ of the retail price is tax.
\end{abstract}

Key words: Tobacco epidemic, Tobacco control, FCTC, MPOWER

\section{ÖZET}

Tütün salgını, dünyanın şimdiye kadar karşılaştığı en büyük halk sağlı̆̆ı tehditlerinden biridir ve yılda 7 milyondan fazla insanın ölümüne yol açmaktadır. Bu ölümlerin 6 milyondan fazlası doğrudan tütün kullanımının bir sonucu iken, yaklaşık 890.000'i sigara içmeyenlerin pasif olarak sigara dumanına maruz kalmasının sonucudur. Dünya genelinde 1,1 milyar kişi tütün ve tütün ürünü kullanmaktadır ve sigara içenlerin yaklaşık \% 80'i düşük ve orta gelirli ülkelerde yaşamaktadır. Dünya Sağlık Örgütü Tütün Kontrolü Çerçeve Sözleşmesi (DSÖ TKÇS) Şubat 2005 'te yürürlüğe girmiştir ve dünya nüfusunun \% 90'ından fazlasını kapsayan 181 ülke tarafindan kabul edilmiştir. DSÖ TKÇS kişilerin en yüksek sağlı standardına sahip olma haklarını teyit eder, uluslararası sağlık işbirliği için yasal boyutlar sağlar ve uyum için yüksek standartlar belirler. Dünya Sağlık Örgütü (DSÖ), 2008 yılında DSÖ TKÇS'nin temel talep azaltma hükümlerinin uygulanmasını ölçeklendirmek için pratik, maliyet-etkin bir yol haritası sunmuştur:MPOWER. Her bir MPOWER politika önerisi, DSÖ TKÇS'nin en az bir hükmüne karşılık gelir. Altı MPOWER politika önerisi şunlardır: Tütün kullanımı ve koruyucu politikaları izlemek, insanları pasif sigara dumanı etkileniminden korumak, sigarayı bırakmak için uygun yardım önermek, tütünün zararları konusunda uyarmak, tütün ürünlerinin reklam, tanıtım ve sponsorluğunu kısıtlama konusunda var olan mevzuatı güçlendirmek ve tütün üzerindeki vergiyi artırmak. Dünya nüfusunun \% 39'unu temsil eden dünya genelindeki ülkelerin üçte ikisinde, ulusal düzeyde genç ve yetişkin sigara kullanım anketlerini en az 5 yılda bir tekrar ederek tütün kullanımını izlemektedir. Dünya nüfusunun\% 33'ünü temsil eden sadece 26 ülkede sigara bırakmaya yardımcı olmak için tam veya kısmi maliyet kapsamına sahip ulusal ve kapsamlı sigara bırakma hizmetleri mevcuttur. Dünya nüfusunun \% 47'sini temsil eden 78 ülke, sigara paketleri üzerinde resimli sağlık uyarılar için en iyi uygulamayı yapmaktadır. Dünya nüfusunun yaklaşık \% 44'ü, son 2 yılda en az bir tane güçlü tütün kullanımı karşıtı kitle iletişim kampanyası düzenleyen 43 ülkede yaşamaktadır. Dünya nüfusunun \% 15 'ini temsil eden sadece 37 ülke, her türlü tütün reklamı, tanıtım ve sponsorluğunu tamamen yasaklamıştır. Dünya nüfusunun \% 10'unu oluşturan sadece 32 ülke, tütün ürünlerine vergiler getirmiş, böylece sigara perakende satış fiyatının \% 75'inden fazlasını vergiler oluşturmuştur. Anahtar kelimeler: Tütün salgını, Tütün kontrolü, TKÇS, MPOWER

Received Date / Geliş tarihi: 15.05.2018, Accepted Date / Kabul tarihi: 18.05.2018

${ }^{1}$ Sağlık Bilimleri Üniversitesi Gülhane Tıp Fakültesi Halk Sağlığı Anabilim Dalı, ANKARA

*Address for Correspondence / Yazışma Adresi: Toker Ergüder, Sağlık Bilimleri Üniversitesi Gülhane Tıp Fakültesi Halk Sağlı̆̆ Anabilim Dal, ANKARA

E-mail: ergudert@ who.int

Ergüder T. Küresel Tütün Kullanımı Salgını ve Kontrolü. TJFMPC, 2018;12(4)301-306:

DOI: $10.21763 /$ tjfmpc.465777 


\section{GİRIŞ}

Günümüzde tütün kullanımı iskemik kalp hastalığı, kanser, inme ve solunum yolu hastalıkları dahil olmak üzere pek çok hastalıktan ölme riskini artırmaktadır ve dünyanın tek başına en önemli önlenebilir ölüm nedeni ve halk sağllğ̆ sorunudur. ${ }^{1}$ Tütün kullanımı dünya genelinde her yıl yaklaşık 7,1 milyon kişinin $(5,1$ milyon erkek ve 2 milyon kadın) ölümüne neden olmaktadır. Bu ölümlerin büyük bir kısmı sigara içimine bağlı olarak $(6,3$ milyon) ve 884 bini pasif olarak sigara dumanına bağlı olarak meydana gelmektedir. ${ }^{2} 2030$ y1lına gelindiğinde bu sayı 8 milyonu aşacak ve acil önlemler alınmadığı takdirde bu yüzyıl boyunca tütün kullanımı 1 milyar kişinin ölümüne neden olacaktır. Tütün, tüketicisine zarar veren yegane yasal üründür; bilindiği üzere kullanıcılarının yarısını öldürmektedir. Bununla birlikte tütün kullanımı bütün dünyada oldukça yaygın bir davranıştır. ${ }^{1}$ Dünya genelinde 942 milyonu erkek ve 175 milyonu kadın olmak üzere yaklaşık 1,1 milyar kişi sigara içmektedir (15 yaş ve üzeri). ${ }^{2}$ Sigara fiyatlarının ucuz oluşu, yaygın ve saldırgan pazarlama teknikleri, tütün kullanımının tehlikeleri hakkındaki bilgi yetersizliği ve tütün kullanımına karşı etkili politikaların olmayışı bunda rol oynamaktadır.

Tütün kullanımının sağlığa verdiği zararlar uzun y1llar bilinmemiştir. Bunun sonucu olarak tütün kullanımı salgın şeklinde artmaya başlamış ve buna bağlı ölümler de artmıştır.

\section{Dünya Sağllk Örgütü Tütün Kontrolü Çerçeve Sözleşmesi (DSÖ TKÇS)}

Dünya Sağlık Örgütü 1999 yılında, tütün salgınının yayılmasının halk sağlığı için ciddi sonuçları olduğunu kabul ederek, salgının önlenmesine ve mümkün olan en etkin, uygun ve kapsamlı uluslararası tepkinin verilmesine imkan sağlayacak uluslararası bir Çerçeve Sözleşmesi hazırlıklarına başlamıştır. $^{3} 2003$ yılında Dünya Sağlık Örgütü Tütün Kontrolü Çerçeve Sözleşmesi ${ }^{4}$ tütün salgınının mümkün olan en geniș uluslararası işbirliğini ve tüm ülkelerin katılımını gerektiren küresel bir sorun olduğunu kabul ederek ve uluslararası toplumun, tütün tüketiminin ve tütün dumanına maruz kalmanın, dünya çapında tahrip edici sağlık, sosyal, ekonomik ve çevresel sonuçları ile ilgili kaygılarını yansıtarak DSÖ’ne üye ülkeler tarafindan kabul edilmiştir. Sözleşme, tütün kontrolü ile ilgili olarak birçok devlet tarafından yürütülen değerli çalışmaların ve tütün kontrolü alanında önlemlerin geliştirilmesinde Dünya Sağlık Örgütü'nün liderliğini ve Birleşmiş Milletler sisteminin diğer kuruluş ve organları ile diğer uluslararası ve hükümetler arası bölgesel örgütlerin çabalarını göz önüne alarak ve sivil toplum örgütlerinin ve profesyonel sağlı kurumları, kadınlar, gençler, çevre ve tüketici grupları, akademik kuruluşlar ve sağlık kuruluşları gibi tütün endüstrisi ile bağlantısı olmayan diğer sivil toplum üyelerinin tütün kontrolünde ulusal ve uluslararası alandaki özel katkılarını ve bu faaliyetlere katılımlarının hayati önemini vurgulayan ilk halk sağlığ1 sözleşmesidir. Sözleşme tüm üye devletleri tütün endüstrisinin, tütün kontrolündeki çabaları bozma ve yıpratma girişimlerine karşı tetikte olunması gerektiğini ve tütün endüstrisinin tütün kontrolü çabalarında olumsuz etkilere neden olabilecek faaliyetlerinden haberdar olunmas1 gerektiği hususunda uyarmaktadır.

Türkiye söz konusu sözleşmeyi 28 Nisan 2004 tarihinde imzalamış ve 25/11/2004 tarihli ve 5261 sayılı Kanunla onaylamıştır. ${ }^{4}$

Dünya Sağlık Örgütü Tütün Kontrolü Çerçeve Sözleşmesi tütün arzını ve talebini azaltma amacıyla ülkelere aşağıdaki hedefleri koymaktadır. ${ }^{5}$

1) Tütüne talebi azaltmaya yönelik önlemler

a. Tütüne talebin azaltılması için fiyat ve vergi önlemleri (Madde 6)

b. Tütüne talebi azaltmada fiyat dışı önlemler

i. Tütün dumanından korunma (Madde 8)

ii. Tütün ürünlerinin içerikleri ile ilgili düzenleme (Madde 9)

iii. Tütün ürünlerinin ifşası ile ilgili düzenleme (Madde 10)

iv. Tütün ürünlerinin paketlenmesi ve etiketlenmesi (Madde 11)

v. Öğretim, iletişim, eğitim ve toplumsal bilinç (Madde 12)

vi. Tütün reklamı, promosyonu ve sponsorluğu (Madde 13)

vii. Tütün bağımlılığı ve tütünün bırakılması ile ilgili talep azaltıcı önlemler (Madde 14)

2) Tütün arzının azaltılmasına yönelik önlemler

a. Tütün ürünlerinin yasa dışı ticareti (Madde 15)

b. Çocuklara ve çocuklar aracılığıyla satış yapılması (Madde 16)

c. Ekonomik açıdan uygun alternatif faaliyetler için destek sağlanması (Madde 17)

Dünya Sağlık Örgütü Tütün Kontrolü Çerçeve Sözleşmesi'nin 5,3. maddesine göre, uluslararası sözleşmeyi imzalayan ve taraf olan tüm üye devletler, tütün kontrolü ile ilgili halk sağlığ politikaları geliştirilmesinde ve uygulanmasında, ulusal kanunlar doğrultusunda, bu politikaları tütün endüstrisinin ticari ve diğer çıkar çevrelerinden koruyacakları konusunda taahütte bulunmuşlardır. ${ }^{5}$ 
Dünya Sağlık Örgütü'ne üye 194 ülkeden 181 'i sözleşmeyi imzalayarak 27 Şubat 2005 tarihinde yürürlüğe giren antlaşmaya taraf olmuşlardır. ${ }^{6}$

\section{Dünya Sağlık Örgütü MPOWER Politika Paketi}

DSÖ Tütün Kontrolü Çerçeve Sözleşmesi 181 taraf ülkenin ortak antlaşmasıdır ve tütün salgınına karşı savaşta çok önemli bir adımdır. Bu antlaşma tütün arzını ve talebini azaltma yolunda ülkelere ayrıntılı bilgiler vermektedir. DSÖ Çerçeve Sözleşmesi uluslararası bir yasa niteliğindedir ve hastalıklardan korunma ve sağlığı geliştirme bakımından hayati öneme sahiptir. DSÖ Çerçeve Sözleşmesine taraf olan ülkeler tütün salgınına karşı mücadeleye katılarak ülkelerindeki halkın sağlığını koruma konusunda söz vermişlerdir. Ülkelere bu yönde yardım etmek amacı ile DSÖ 2007 yılında MPOWER paketini hazırlamıştır. ${ }^{1} \mathrm{Bu}$ pakette tütün kontrol politikası olarak en etkili 6 politika ele alınmaktadır:

1) Vergileri ve fiyatı artırmak,

2) Reklam, tanıtım ve sponsorluğu yasaklamak,

3) Toplumları pasif sigara dumanı etkileniminden korumak,

4) Herkesi sigaranın tehlikeleri konusunda uyarmak,

5) Sigarayı bırakmak isteyenlere yardım etmek,

6) Salgını ve koruyucu uygulamaları titizlikle izlemek.

$\mathrm{Bu}$ politikaların tütün kullanımını azalttığı kanıtlanmıştır. MPOWER'1 desteklemek üzere DSÖ ve küresel ortakları, tütün kullanımına bağlı hastalık ve ölümlerle ekonomik hasarları durdurma çabalarında ülkelere yardımcı olabilmek için yeni kaynaklar yaratmaktadır. Bu altı politika paket olarak uygulandığı ve zorlandığ takdirde gençlerin sigaraya başlaması önlenmekte, sigara içenlere bırakmaları için destek sağlanmakta, sigara içmeyenler pasif sigara dumanı etkileniminden korunmakta ve toplumlar sigaranın zararlarından korunmuş olmaktadır.

2017 yılı itibariyle DSÖ'ne üye devletlerin yaklaşık üçte ikisi (121/194) - bu oran dünya nüfusunun $\% \quad 63$ 'ünü $\quad(4,7$ milyar kişi $)$ oluşturmaktadır - üstte belirtilen MPOWER politikalarının birini en iyi şekilde uygulamıştır. Bu politikaların 2 veya daha fazlasını uygulayan ülke sayısı 71 olup toplamda 3,2 milyar kişiyi tütün salgınından korumaktadır. Sekiz ülke (Brezilya, İran, İrlanda, Madagaskar, Malta, Panama, Türkiye, İngiltere ve Kuzey İrlanda) 4 veya daha fazla MPOWER politikasını uygulamaya koymuştur. Türkiye 2012 yılından bu yana bu politika paketinin tümünü birden uygulayan dünya genelindeki ilk ve tek ülkedir. ${ }^{7}$
Tütün kullanımı ve koruyucu politikaların izlenmesi

Tütün kullanımı ve buna bağlı etkiler konusundaki değerlendirmeler güçlendirilmelidir. Halen ülkelerin yarısında (gelişmekte olan ülkelerin üçte ikisinde) gençlerin ve yetişkinlerin sigara kullanımı konusunda asgari bilgileri bile yoktur. Tütüne bağl1 hastalıklar ve ölümler gibi salgının diğer boyutları konusunda da bilgi yetersizdir. İyi bir izleme ile ülkede salgının boyutları konusunda bilgi edinilebilir ve ülkenin gereksinmesine özel politikalar geliştirilebilir. Tütün salgınını iyi anlamak ve tersine çevirmek için küresel düzeyde ve ülkeler bazında bilgiye gereksinim vardır. 2016 yılı itibariyle dünya genelinde tütün kullanımını ve koruyucu politikaları ulusal düzeyde araştırmalarla izleyen ülke saysı $76^{\prime}$ 'dır ve dünya nüfusunun \%39'unu (2,9 milyon kişi) oluşturmaktadır. ${ }^{7,8}$

\section{İnsanları pasif sigara dumanı etkileniminden korumak}

Temiz hava solumak herkes için temel bir haktır. Sigarasız, dumansız ortamlar hem sigara içmeyenleri koruyan, hem de sigara içenleri bırakmaları konusunda destekleyen bir yaklaşımdır. Gelir düzeyinden bağımsız olarak bütün ülkeler sigarasız ortam ile ilgili yasaları etkili şekilde uygulayabilirler. Bununla birlikte dünya nüfusunun ancak \%5'i kapsamlı sigarasızlık yasası ile korunmaktadır. Çoğu ülkede sigarasızlık yasaları bazı kapalı alanları kapsamaktadır, güçlü değildir ve uygulama da tam değildir. Aslında bu konuda bir yasa çıkarıldıktan ve uygulamaya girdikten sonra çok popüler olmakta ve sigara içenler tarafından da desteklenmektedir, işyerlerini de olumsuz olarak etkilememektedir. Yalnızca tam sigarasız alanlar uygulaması insanları sigara dumanından etkili şekilde korur ve sigara içenlere de brrakmaları konusunda yardımcı olur. Kapsamlı yasalarla kapalı tüm alanlarda sigara içmeyi yasaklayan ülke sayısı 2016 y1l itibariyle 55 'dir ve dünya nüfusunun \%20'sini (1,5 milyar kişi) oluşturmaktadır. ${ }^{7,8}$

\section{Sigarayı bırakmak için uygun yardım önermek}

Dünyada sigara içen bir milyarın üzerindeki kişinin (yetişkin nüfusun dörtte biri) çoğu bağımlıdır. Pek çoğu sigarayı bırakmak ister, ancak pek azı gereksinim duyduğunda bu konuda yardım alabilir. Tütün bağımlılığ 2016 yılı itibariyle 26 ülkede vardır, bu da sigara içenlerin \%5'i kadardır. Ülkeler; sigara kullanan ve bırakmak isteyenlere yönelik olarak etkili ve ucuz müdahale programları oluşturmalıdır. ${ }^{7,8}$ 


\section{Tütünün zararları konusunda uyarmak}

Bu konudaki ikna edici kanıtlara karşın sigara içenlerin pek azı sigara kullanımına bağlı sağlık sorunlarını bütün boyutları ile bilmektedir. Tütün kullanımının tehlikeleri konusunda kapsamlı uyarılar adolesan ve genç yetişkinler arasında sigaranın imajını değiştirebilir. Dünyada, 78 ülkede sigara paketleri üzerinde (paketin ana yüzünün \%50'sini kaplayacak şekilde) resimli uyarı yasal zorunluluktur. 2012 yilında Avustralya sigara paketlerinde tek tip (düz paket) paket uygulamasına geçmiştir. 31 Aralık 2017 tarihi itibariyle Avustralya, Fransa, Macaristan, İrlanda, Norveç ve İngiltere düz paket uygulamasına geçmişlerdir. ${ }^{9,10}$ Dünya nüfusunun \%40'ının yaşamakta olduğu ülkelerde "hafif (light)", "düşük katranlı (low-tar)" gibi yanıltıcı ve aldatıcı ifadelere karşı koruma yoktur. $\mathrm{Bu}$ uygulamanın sağlık riskini azaltıcı herhangi bir etkisinin olmadığı tütün endüstrisi tarafindan da uzun zamandan beri bilmektedir. ${ }^{7,8}$

Tütün ürünlerinin reklam, tanıtım ve sponsorluğunu kısıtlama konusunda var olan mevzuatı güçlendirmek

Tütün endüstrisi her yıl sigara reklamı, tanıtımı ve sponsorluğu için on milyarlarca dolar harcamaktadır. Reklam, tanitım ve sponsorluk konusunda kısmi yasak işe yaramamaktadır; zira endüstri, kaynaklarını hemen yasak olmayan diğer kanallara yöneltmektedir. Yalnızca tam olarak yasaklama insanları, özellikle de gençleri tütün endüstrisi taktiklerinden koruma konusunda başarılı olmakta ve sigara kullanımında azalma sağlamaktadır. Halen dünya nüfusunun ancak \%15'i (37 ülke) tütün reklam, tanitım ve sponsorluğu konusunda kapsamlı yasakların olduğu ülkelerde yaşamaktadır. Dünyadaki çocukların yaklaşık yarısı tütün ürünlerinin ücretsiz olarak dağıtılmasının yasak olmadığı ülkelerde yaşamaktadır. ${ }^{7,8}$

\section{Tütün üzerindeki vergiyi artırmak}

Vergilerin, dolayısı ile sigara fiyatının artırılması sigara kullanımını azaltmada en etkili yoldur. Sigara fiyatının artırılması özellikle gençlerin sigaradan uzak kalmasını sağlamaktadır. Bu uygulama ayrıca sigara içenlerin de sigarayı bırakmasına yardımcıdır. Dünyada, sadece 32 ülkede sigara satış fiyatının $\% 75^{\prime} \mathrm{i}$ kadar vergi uygulanmaktadır. ${ }^{7,8}$ Sigara fiyatında \%70'lik artış, dünyada tütüne bağlı ölümlerde \%25'lik azalma sağlayabilir. Sigara fiyatının \%10 artırılması yüksek gelirli ülkelerde sigara kullanımında $\% 4$, orta ve düşük gelirli ülkelerde de $\% 8$ oranında azalmaya yol açabilir. $\mathrm{Bu}$ durumda sigara kullanımı azalmakla birlikte sigara satışından sağlanan vergi gelirlerinde azalma olmaz. Vergilerin artırılması yoluyla tütün kontrolü amacı ile kullanılmak üzere maddi kaynak sağlanabilir, bu kaynak halk sağlığ ile ilgili diğer alanlarda ve sosyal programlarda da kullanılabilir. $\mathrm{Bu}$ konuda bilgi toplayan ülkelerde tütün satışından sağlanan vergi gelirlerinin, tütün kontrolü için kullanılan miktarın 500 katı olduğu görülmektedir. Orta ve düşük gelirli ülkelerden edinilen bilgilere göre 3,8 milyar dolarlık vergi gelirine karşılık, tütün kontrolü amacı ile kullanılan miktar yılda sadece 14 milyon dolar olmuştur. Öte yandan bazı ülkelerde vergi gelirleri 66,5 milyar dolara kadar çıkmaktadır. Bir başka ifade ile her 5000 dolarlık vergi gelirine karş1lık tütün kontrolü için sadece 1 dolar harcanmaktadır. Düşük gelirli ülkelerde tütün kontrolü için kişi başına harcama bir sentin onda birinden azdır, orta gelirli ülkelerde de yarım sent kadardır. ${ }^{7,8}$

\section{SONUC}

Tütün kullanımının tehlikeleri sosyo-ekonomik sınır tanımamakla birlikte, tütün salgınının hasarı, düşük gelirli toplumlarda ve ülkelerde daha çok görülür. Bu ülkelerde tütün kullanımı artmaktadır, buna karşılık tütün kullanımının yol açacağı sağlık, sosyal ve ekonomik sorunlara cevap verecek yeterli kaynak yoktur. Tütün endüstrisi de özellikle bu ülkeleri hedef almakta ve bu ülkelere yönelik pazarlama ve tanıtım yapmaktadır. Bütün ülkelerde hükümetler ve sivil toplum kuruluşlarınım birlikte çalışarak, tütün kullanımını ve buna bağlı sağlık sorunları ile ölümleri azalttığı kanıtlanmış olan altı politikayı kararlılıkla, uygulamaya koymalıdır.

Dünya Sağlık Örgütü 2011 yılında Birleşmiş Milletler Genel Kurulu'nun kabul ettiği Bulaşıcı Olmayan Hastalıkların Önlenmesi ve Kontrolü konulu siyasi bildirisine (66/2 nolu Bulaşıcı Olmayan Hastalıklar Siyasi Bildirisi) uygun olarak "2013-2020 Bulaşıcı Olmayan Hastalıkların Önlenmesi ve Kontrolüne yönelik Küresel Eylem Planı"nı geliştirmiştir. ${ }^{11,12} \mathrm{Bu}$ planı uygulamak amacıyla gerçekleştirilecek eylemlerin değerlendirilmesi için sağl1k durumu, risk faktörleri ve sağlık sistemlerinin kapasitesi ile yanıtına yönelik dokuz gönüllü hedefi ve 25 göstergeyi içeren küresel bir izlem çerçevesi oluşturmuştur. Bu hedefler arasında 2025 yılına kadar bulaşıcı olmayan hastalıklar kaynaklı erken ölümlerin \%25 azaltılması ve 15 yaş ve üstü bireylerde mevcut tütün kullanımı prevalansının 2025 y1lında \%30 azaltılması küresel hedefleri de bulunmaktadır.

Dünya Sağlık Örgütü bu hedefe ulaşılması için tüm ülkeleri;

1) DSÖ TKÇS'nin bütün boyutlarıyla uygulanmasının hızlandırılması Dünya Sağlık Asamblesi 56.1 sayıl1 $^{12}$ karara ve Bulaşıcı Olmayan Hastalıkların Önlenmesi ve 
Kontrolüne İlişkin Üst Düzey Genel Kurul Toplantıs1 Siyasi Bildirgesine ${ }^{11}$ uygun olarak, DSÖ TKÇS'ye henüz taraf olmayan üye devletleri en k1sa sürede bu sözleşmenin tasdikine, kabulüne, onaylanmasına, resmi olarak teyidine veya sözleşmeye taraf olunmasına ilişkin eyleme geçmeye,

2) Tütün kullanımını ve tütün dumanına maruziyeti azaltmak amaciyla, çok sektörlü kapsamlı bir paketin uygulanması için DSÖ Tütün Kontrolü Çerçeve Sözleşmesi Taraflar Konferansinca benimsenen rehberi kullanmaya,

3) DSÖ TKÇS'nin 5.3. maddesine ve ulusal hukuka uygun olarak, tütün kontrolü politikalarının tütün endüstrisinin ticari ve diğer çıkarlarından korumaya,

4) DSÖ TKÇS'nin 8. maddesine (tütün dumanına maruziyetten korunma) uygun olarak bütün kapalı işyerlerinde, toplu taşıma araçlarında, kamuya açık kapalı alanlarda ve gerekli diğer kamusal alanlarda \%100 dumansiz ortamlar sağlanması amaciyla mevzuat çalışması yürütmeye,

5) DSÖ TKÇS'nin 11. maddesine (tütün ürünlerinin ambalajlanması ve etiketlenmesi) ve 12. maddesine (eğitim, iletişim, öğretim ve kamuoyu farkındalığı) uygun olarak, insanların tütün kullanımının zararları konusunda uyarılması ve bu kapsamda kanıta dayalı sarsıcı kitle iletişim kampanyalarının ve büyük, net, görünür ve okunaklı sağlı uyarıları kullanmaya,

6) DSÖ TKÇS'nin 13. maddesine (tütün ürünlerinin reklamı, promosyonu ve sponsorluğu) uygun olarak tütün reklamlarına, promosyonuna ve sponsorluğuna kapsamlı yasakları uygulamaya,

7) DSÖ TKÇS'nin 14. maddesine (tütün bağımlılığı ve bırakma ile ilgili talep azaltıcı önlemler) uygun olarak, tütün kullanımını bırakmak isteyenlere yönelik hizmetleri sağlamaya ve başta gebeler olmak üzere bireyleri çevresel tütün dumanına maruziyetten korumaya,

8) DSÖ TKÇS’nin 9. maddesine (tütün ürünlerinin muhteviyatının düzenlenmesi) ve 10. maddesine (tütün ürünlerine ilişkin beyanların düzenlenmesi) uygun olarak, tütün ürünlerinin içeriğinin ve emisyonlarının düzenlenmesi ve tütün üretici ve ithalatçılarının tütün ürünlerinin içeriğini ve emisyonlarını hükümet mercilerine beyan etmelerini gerekli k1lmaya,

9) Bulaşıcı Olmayan Hastalıkların Önlenmesi ve Kontrolüne İlişkin Üst Düzey Genel Kurul Toplantıs1 Siyasi Bildirgesine ve DSÖ TKÇS'nin 6. maddesine (tütüne talebin azaltılmasına yönelik fiyat ve vergi önlemleri) uygun olarak, tütün ürünlerinin tüketiminin azaltılması amaciyla bütün tütün ürünlerine uygulanan vergileri artırmaya,

10) Küresel izleme çerçevesinin göstergelerine göre özellikle gençlerin sigaraya başlama oranları ve mevcut tütün kullanım oranları olmak üzere tütün kullanımının izlemeye ve DSÖ TKÇS'nin 20. maddesine (araştırma, sürveyans ve bilgi alışverişi) ve 21. maddesine (raporlama ve bilgi alışverişi) uygun olarak tütün kontrol politika ve önlemlerinin uygulanmasını izlemeye,

11) DSÖ TKÇS'nin 5. maddesine (genel yükümlülükler) uygun olarak tütün kontrolü için bir ulusal koordinasyon mekanizması veya irtibat noktaları oluşturmaya veya mevcut olanları güçlendirmeye ve finanse etmeye,

12) DSÖ TKÇS'nin 26. maddesine (mali kaynaklar) uygun olarak, benimsenen tütün kontrolü politikalarını uygulamak için gerekli mekanizmaları kurma ve güçlendirmeye ve finanse etmeye davet etmektedir.

Tütün salgını dünyayı salgınlardan daha çok tehdit etmektedir. Ancak bu durumun çözümü için bir ilaç veya aşının keşfedilmesi gerekmemektedir. Başarısı kanıtlanmış olan politikaların uygulamaya konması ile bu salgın kontrol edilebilir. Tütün salgınının tedavisi hükümet başkanlarının veya bu konularda aktif olarak çalışan sivil toplum örgütlerinin elindedir, çünkü tütün kontrolü ile ilgili bütün yöntemler politik kararlılık gerektirir. Vatandaşlarının sağlığını korumak için yapmaları gereken, yukarıda sözü edilen yöntemleri uygulamaya koymalarıdır. Tütün endüstrisi, çocukları ve sigara içmeyenleri tütün dumanından korumak ve sigarayı birakmak isteyenlere yardım etmek konularında savunuculuk yapanlardan çok daha fazla maddi olanağa sahiptir, bu yüzden tütün salgınını tersine çevirebilmek için bütün ülkelerde daha fazla çaba gösterilmelidir. Hükümetler ve sivil toplum MPOWER politikalarını uygulamaya koymak için harekete geçerek; hükümetler ve sivil toplum sigarasız ortamlar yaratabilirler.

\section{KAYNAKLAR}

1. World Health Organization, WHO Report on the Global Tobacco Epidemic, 2008: The MPOWER package. Geneva, World Health Organization, 2008. Erişim, 30 Mart 2018. http://apps.who.int/iris/bitstream/handle/10665/ 43818/9789241596282 eng.pdf;jsessionid=B1 F73F6F256330268F4EDEDDEF4E0FB8?sequ ence $=1$

2. Drope J, Schluger N, Cahn Z, Drope J, Hamill S, Islami F, Liber A, Nargis N, Stoklosa M. 2018. The Tobacco Atlas. Atlanta: American Cancer Society and Vital Strategies. Erişim, 6 
Nisan 2018. https://tobaccoatlas.org/wpcontent/uploads/2018/03/TobaccoAtlas 6thEdi tion_LoRes_Rev0318.pdf

3. World Health Organization, The WHO Framework Convention on Tobacco Control: an overview, Erişim, 30 Mart 2018. http://www.who.int/fctc/WHO_FCTC_summar y_January2015_EN.pdf

4. Dünya Sağlık Örgütü Tütün Kontrolü Çerçeve Sözleşmesi Milletlerarası Sözleşme, Resmi Gazete, Erişim, 6 Nisan 2018. http://www.resmigazete.gov.tr/main.aspx?hom $\mathrm{e}=\mathrm{http} / /$ www.resmigazete.gov.tr/eskiler/2004/ 12/20041225.htm\&main=http://www.resmigaz ete.gov.tr/eskiler/2004/12/20041225.htm

5. WHO Framework Convention on Tobacco Control. World Health Organization. ISBN 978 9241591010 (LC/NLM classification: HD 9130.6) World Health Organization 2003, updated reprint 2004, 2005, Erişim, 6 Nisan 2018

http://apps.who.int/iris/bitstream/handle/10665/ 42811/9241591013.pdf?sequence $=1$

6. Parties to the WHO Framework Convention on Tobacco Control, Erişim, 12 Nisan 2018. http://www.who.int/fctc/signatories_parties/en/

7. WHO report on the global tobacco epidemic, 2017: Monitoring tobacco use and prevention policies. Geneva: World Health Organization; 2017. Licence: CC BY-NC-SA 3.0 IGO. Erişim $\quad 12 \quad$ Nisan 2018. http://apps.who.int/iris/bitstream/handle/10665/ 255874/9789241512824-

eng.pdf;jsessionid=07903B4FB54A677D5B1A $\underline{B} 7628 D A D F 7 D 4$ ?sequence $=1$

8. DSÖ Küresel Tütün Salgını Raporu, 2008; MPOWER paketi, Cenevre, Dünya Sağlık Örgütü, 2008, Erişim, 12 Nisan 2018 http://apps.who.int/iris/bitstream/handle/10665/ 43818/9789241596282_tur.pdf?sequence $=6$

9. Plain packaging of tobacco products: evidence, design and implementation. World Health Organization. ISBN 9789241565226 (NLM classification: WM 290), Erişim, 19 Nisan 2018.

http://www.who.int/tobacco/publications/indus try/plain-packaging-tobacco-products/en/

10. Campaign for Tobacco-Free Kids, Plain or Standardized Tobacco Packaging: International Developments - Updated December 2017, Erişim $19 \quad$ Nisan 2018. https://www.tobaccofreekids.org/assets/global/ pdfs/en/standardized_packaging_devedevelop $\underline{\text { ments_en.pdf }}$

11. Birleşmiş Milletler Genel Kurulu 66/2 sayılı kararı "Bulaşıcı Olmayan Hastalıkların önlenmesi ve kontrolü konulu Siyasi Bildirisi”, Erişim, $\quad 12 \quad$ Mayıs 2018. http://www.who.int/nmh/events/un_ncd_summ it2011/political_declaration_en.pdf?ua $=1$

12. Global action plan for the prevention and control of noncommunicable diseases 20132020. ISBN 978924150623 6, World Health Organization 2013, Erişim, 12 Mayıs 2018. http://apps.who.int/iris/bitstream/handle/10665/ 94384/9789241506236 eng.pdf?sequence $=1$

13. Bulaşıcı olmayan hastalıkların önlenmesine ve kontrolüne ilişkin küresel eylem planı 20132020, Erişim, 12 Nisan 2018. file:///C:/Users/user1/Desktop/\%252FEkutupha ne\%252Fkitaplar\%252Fbula\%C5\%9F\%C4\%B 1c\%C4\%B1\%20olmayan\%20hastal\%C4\%B1k $\underline{\operatorname{lar} \% 20(1) \cdot p d f}$ 